\title{
ANALISIS PENGENDALIAN KUALITAS MENGGUNAKAN DIAGRAM KENDALI DEMERIT PADA KUALITAS PRODUK PT. SINAR SOSRO KPB UNGARAN
}

\author{
FANNY PRIMANDA PITER, YUDIANTRI ASDI*, HAZMIRA YOZZA \\ Program Studi S1 Matematika, \\ Fakultas Matematika dan Ilmu Pengetahuan Alam, Universitas Andalas, \\ Kampus UNAND Limau Manis Padang, Indonesia. \\ email : fannypiter@gmail.com,yudiantriasdi@sci.unand.ac.id,hazmirayozza@sci.unand.ac.id
}

Diterima 15 September 2020 Direvisi 14 Oktober 2020 Dipublikasikan 21 Oktober 2020

\begin{abstract}
Abstrak. Suatu bentuk dasar konsep kualitas sering diartikan sebagai ukuran kebaikan suatu produk atau jasa yang terdiri atas kualitas desain dan kualitas kesesuaian. Terdapat banyak alat yang bisa digunakan dalam proses pengendalian kualitas produk. Dua diantaranya adalah Diagram Pareto dan Diagram Kendali Demerit. Tujuan dari penelitian ini adalah untuk menentukan apakah proses produksi Teh Botol Sosro KPB Ungaran terkendali dan mengidentifikasi jenis cacat yang paling mendominasi pada proses produksi Teh Botol Sosro KPB Ungaran. Hasil dari penelitian ini adalah proses produksi tidak terkendali secara statistik yang disebabkan oleh faktor volume tidak standar. Ini terjadi karena unit filling valve yang rusak sehingga dapat menyebabkan volume produk tidak sesuai dengan standar. Dan jenis cacat yang paling mendominasi adalah jenis cacat mayor.

Kata Kunci: Kualitas, Diagram Kendali Demerit, Diagram Pareto
\end{abstract}

\section{Pendahuluan}

Teh adalah minuman yang mengandung kafeina, sebuah infusi yang dibuat dengan cara menyeduh daun atau pucuk daun yang dikeringkan dari tanaman Camellia sinensis dengan air panas. Di Indonesia, teh dalam kemasan botol ini pertama kali muncul dalam merek Teh Botol Sosro. Teh Botol Sosro tidak akan bertahan tanpa ada konsumen yang mempergunakan atau memakai produk yang dihasilkan pihak produsen. Oleh karena itu, Teh Botol Sosro harus selalu menjaga agar kualitas teh yang diproduksinya selalu memenuhi harapan konsumen.

Pengendalian kualitas statistik dapat dilakukan terhadap indikator-indikator kualitas yang ditetapkan perusahaan dengan menggunakan berbagai alat analisis data. Dua diantaranya adalah Diagram Pareto dan Diagram Kendali Demerit. Pada

*penulis korespondensi 
penelitian ini akan dilakukan proses pengendalian kualitas terhadap produk Teh Botol Sosro dengan memanfaatkan data frekuensi cacat berbagai jenis yang terjadi pada produk tersebut. Untuk menggambarkan berbagai masalah kecacatan tersebut, dapat digunakan Diagram Pareto. Dengan diagram ini dapat ditentukan cacat apa yang mendominasi pada produk tersebut.

Untuk data cacat, terdapat jenis kecacatan dengan tingkat keparahan yang berbeda yang dikategorikan menjadi cacat minor, mayor, dan kritis seperti yang ditemui pada produksi Teh Botol Sosro ini maka diagram kendali yang paling sesuai adalah Diagram Kendali Demerit. Tujuan dari penelitian ini adalah menentukan apakah proses produksi Teh Botol Sosro KPB Ungaran terkendali dan mengidentifikasi jenis cacat yang paling mendominasi pada proses produksi Teh Botol Sosro KPB Ungaran.

\section{Landasan Teori}

\subsection{Definisi Kualitas}

Suatu bentuk dasar konsep kualitas sering diartikan sebagai ukuran kebaikan suatu produk atau jasa yang terdiri atas kualitas desain dan kualitas kesesuaian.

\subsection{Pengendalian Kualitas}

Pengendalian kualitas adalah aktivitas produksi dan manajemen, dimana aktivitas tersebut mengukur ciri-ciri kualitas produk, membandingkannya dengan spesifikasi atau persyaratan, dan mengambil tindakan penyehatan yang sesuai apabila ada perbedaan antara penampilan yang sebenarnya dan yang standar [4].

\subsection{Diagram Pareto}

Diagram Pareto merupakan salah satu alat yang sering digunakan dalam pengendalian kualitas. Pada dasarnya Diagram Pareto adalah grafik batang yang menunjukkan masalah berdasarkan urutan banyaknya jumlah kejadian dari batang grafik tertinggi hingga grafik terendah. Dalam aplikasinya, Diagram Pareto bermanfaat dalam menentukan dan mengidentifikasi prioritas masalah yang akan diselesaikan.

\subsection{Diagram Kendali}

Diagram kendali merupakan metode grafik yang digunakan untuk mengevaluasi apakah suatu proses berada dalam proses yang terkendali secara statistik atau tidak. Sebuah keadaan dikatakan terkendali apabila sumber variasinya hanya berasal dari sebab-sebab umum (alamiah). Dengan cara itu dapat mempercepat tindakan untuk memperbaiki dan menyingkirkan variasi khusus tersebut.

\subsection{Diagram Kendali Demerit}

Diagram Kendali Demerit merupakan diagram pengendali dimana jenis cacat dikategorikan menjadi beberapa kelas menurut tingkat kepentingan cacatnya. Pola cacat secara umum berdasarkan bobot cacatnya diklasifikasikan ke beberapa kelas. 
(1) Cacat kelas A (Kritis), yaitu unit akan menyebabkan kecacatan yang tidak mudah untuk diperbaiki sehingga produk sama sekali tidak dipasarkan.

(2) Cacat kelas B (Mayor), yaitu unit yang kecacatannya akan meningkatkan biaya perawatan dan bila mengalami kecacatan dapat mengurangi kualitas produk.

(3) Cacat kelas C (Minor), yaitu unit memiliki ketidaksempurnaan kecil dalam bentuk akhir, penampilan atau kualitas pekerjaan tidak menyebabkan kegagalan dalam pelayanan.

Pada sebuah proses biasanya perusahaan menetetapkan nilai Acceptance Quality Level (AQL) yang merupakan nilai maksimum persen defect untuk sampel inspeksi sebagai bahan pertimbangan tingkat kepuasan pembeli.

Misal $C_{A}, C_{B}, C_{c}$ masing-masing menunjukkan jumlah cacat atau kerusakan pada kelas $A, B$, dan $C$, serta $w_{A}, w_{B}, w_{C}$, masing-masing menunjukkan bobot cacat pada masing-masing kelas. Bobot cacat pada masing-masing kelas dapat ditentukan dengan [3]:

$$
w=\frac{1}{A Q L} \times \operatorname{Total} A Q L
$$

Jumlah cacat terboboti pada tiap subgrup dapat dicari dengan mengalikan jumlah cacat pada masing-masing kelas di tiap subgrup pengamatan dengan faktor bobot yang telah ditentukan perusahaan. Faktor bobot cacat di setiap subgrup pengamatan ditentukan dengan rumus berikut [3]:

$$
\begin{aligned}
& \text { Jumlah cacat terboboti kelas } A: w_{A} C_{A} \text {, } \\
& \text { Jumlah cacat terboboti kelas } B: w_{B} C_{B}, \\
& \text { Jumlah cacat terboboti kelas } C: w_{C} C_{C} .
\end{aligned}
$$

Setelah didapatkan jumlah cacat masing-masing kelas, untuk menghitung jumlah cacat terbobot untuk masing-masing subgrup pengamatan digunakan dengan persamaan berikut, yaitu[3]:

$$
D_{i}=w_{A} C_{i A}+w_{B} C_{i B}+w_{C} C_{i C} .
$$

Misal $n_{i}$ adalah ukuran sampel yang diambil pada subgrup ke- $i$ dan ukuran sampel sama untuk setiap subgrup $n_{i}=n$, maka dapat dicari rata-rata ketidaksesuaian per unit pemeriksaan untuk masing-masing subgrup pengamatan dengan cara membagi jumlah cacat terboboti $\left(D_{i}\right)$ dengan ukuran sampel pada subgrup pengamatan tersebut dengan menggunakan rumus [3]:

$$
u_{i}=\frac{D_{i}}{n_{i}}=\frac{D_{i}}{n}, \quad i=1,2, \cdots, m .
$$

Nilai $u_{i}$ inilah yang akan di plot.

Selanjutnya akan dicari $\bar{u}_{A}, \bar{u}_{B}, \bar{u}_{C}$ yang akan menunjukkan rata-rnumata cacat per unit untuk kelas $\mathrm{A}$, kelas $\mathrm{B}$, dan kelas $\mathrm{C}$ yang dapat diperoleh dengan cara membagi jumlah cacat pada masing-masing kelas dengan jumlah keseluruhan sampel yang terdapat pada subgrup pengamatan. Nilai $\bar{u}_{A}, \bar{u}_{B}, \bar{u}_{C}$ dinyatakan pada 
persamaan sebagai berikut [3]:

$$
\begin{gathered}
\bar{u}_{A}=\frac{\sum_{i=1}^{m} C_{i A}}{\sum_{i=1}^{m} n_{i}}=\frac{\sum_{i=1}^{m} C_{i A}}{m n} \\
\bar{u}_{B}=\frac{\sum_{i=1}^{m} C_{i B}}{\sum_{i=1}^{m} n_{i}}=\frac{\sum_{i=1}^{m} C_{i B}}{m n} \\
\bar{u}_{C}=\frac{\sum_{i=1}^{m} C_{i C}}{\sum_{i=1}^{m} n_{i}}=\frac{\sum_{i=1}^{m} C_{i C}}{m n} .
\end{gathered}
$$

Garis tengah kurva Diagram Kendali Demerit diperoleh dari rata-rata terboboti dari $\bar{u}_{A}, \bar{u}_{B}, \bar{u}_{C}$ yang dihitung dari [3]

$$
\bar{u}=w_{A} \bar{u}_{A}+w_{B} \bar{u}_{B}+w_{C} \bar{u}_{C} .
$$

Selanjutnya batas kendali dinyatakan sebagai [[3]]:

$$
\begin{aligned}
\text { Batas Kendali Atas }(\mathrm{BKA}) & =\bar{u}+3 \sigma_{u}, \\
\text { Kendali Bawah }(\mathrm{BKB}) & =\bar{u}-3 \sigma_{u} .
\end{aligned}
$$

\section{Pembahasan}

Data dari penelitian ini adalah data sekunder yang bersumber dari internet (www.media.neliti.com) yang merupakan kumpulan pencatatan produk Teh Botol Sosro di PT. Sinar Sosro KPB Ungaran dari tanggal 2 Januari 2013 sampai dengan tanggal 9 Februari 2013 dengan 32 subgrup. Dalam hal ini penelitian memusatkan pada proses produksi botol yang sudah terisi agar dapat diketahui penyebab produk yang mengalami kecacatan.

\subsection{Klasifikasi Jenis Cacat}

Terdapat delapan jenis kecacatan yang diamati pada penelitian ini. Berdasarkan definisi jenis kecacatan tersebut delapan jenis kecacatan tersebut akan diklasifikasikan pada tabel berikut.

Tabel 1. Klasifikasi Jenis Kecacatan

\begin{tabular}{|c|c|c|}
\hline No. & Klasifikasi & Jenis Cacat \\
\hline 1 & & Benda asing \\
\cline { 3 - 3 } & \multirow{3}{*}{ Kritis (A) } & Botol gupil \\
\cline { 3 - 3 } & & Warna tidak standar \\
\cline { 3 - 3 } & & Kosong tertutup \\
\cline { 3 - 3 } 2 & \multirow{2}{*}{ Mayor(B) } & Botol retak \\
\cline { 3 - 3 } & & Suhu tidak standar standar \\
\hline 3 & Minor(C) & Tutup miring \\
\hline
\end{tabular}


370 Fanny Primanda Piter dkk

\subsection{Analisis Data Menggunakan Diagram Kendali Pareto}

Terdapat delapan jenis kecacatan yang diamati pada produk ini. Dari total jenis cacat yang berjumlah 8, terdapat dua jenis cacat yang mendominasi, yakni suhu non standar dan volume non standar. Keduanya dikategorikan sebagai kecacatan mayor.

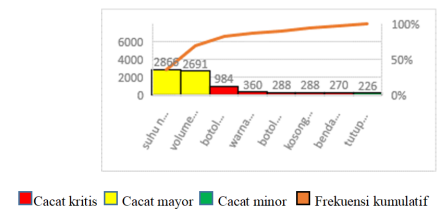

Gambar 1. Diagram Pareto Produk Cacat Teh Botol Sosro

\subsection{Analisis Data Menggunakan Diagram Kendali Demerit}

Data jumlah cacat pada produk Teh Botol Sosro pada tanggal 2 Januari 2013 sampai dengan 9 Februari 2013 dengan sampel 2.500 setiap harinya. Maka selama 32 hari tercatat 80.000 botol. Tanggal-tanggal produksi akan menjadi subgrup pada Diagram Kendali Demerit. Pada tahap pertama, akan dihitung bobot dari masingmasing kelas cacat. Bobot digunakan untuk memberikan tingkat keseriusan terhadap jenis cacat yang ditemukan pada proses produksi. Penentuan didasarkan pada nilai AQL.Untuk Teh Botol Sosro, perusahaan telah menetapkan nilai AQL seperti pada tabel 2 .

Tabel 2. Klasifikasi Jenis Kecacatan

\begin{tabular}{|c|c|c|c|c|}
\hline & Kritis(A) & Mayor(B) & Minor(C) & Total \\
\hline AQL (\%) & 0,065 & 1,000 & 6,500 & 7,565 \\
\hline
\end{tabular}

Berdasarkan tabel di atas didapatkan bobot masing-masing kelas dihitung sebagai berikut: $W_{A}=116,385, w_{B}=7,565$, dan $w_{C}=1,164$. Setelah didapatkan jumlah cacat terboboti pada masing-masing kelas, akan dihitung jumlah dan rata-rata cacat terboboti pada masing-masing subgrup pengamatan. Untuk subgrup ke-1, diperoleh jumlah cacat terboboti sebagai berikut:

$$
D_{1}=9.524,9
$$

Diperoleh juga rata-rata cacat terboboti

$$
u_{1}=3,810
$$

$D_{i}$ dan $u_{i}$ untuk $i=1,2, \cdots, 32$ dapat diperoleh dengan cara yang sama. Selanjutnya akan dicari nilai rata-rata jumlah cacat pada masing-masing kelas. Nilai 
rata-rata jumlah cacat pada masing-masing kelas diperoleh dari jumlah cacat pada tiap kelas dibagi dengan jumlah sampel keseluruhan. Nilai-nilainya adalah sebagai berikut $\bar{u}_{A}=0,027, \bar{u}_{B}=0,070, \bar{u}_{C}=0,002$.

Nilai $\bar{u}_{A}, \bar{u}_{B}, \bar{u}_{C}$ ini selanjutnya akan digunakan untuk menghitung nilai garis tengah dari Diagram Kendali Demerit dengan nilai garis tengah $\bar{u}$ adalah 3,674 . Dan diperoleh nilai simpangan baku dari u $\left(\sigma_{u}\right)$ adalah 0,384 .

Berdasarkan kedua nilai tersebut didapatkan nilai batas kendali atas (BKA) adalah 4,826 dan batas kendali bawah (BKB) adalah 2,522. Selanjutnya nilai $u_{i} ; i=1,2, \cdots, 32$ yang diperoleh diplotkan pada bidang dihubungkan dengan garis. Diagram tersebut dilengkapi dengan garis tengah, nilai BKA, dan BKB. Diagram Kendali Demerit dapat dilihat pada gambar 2.

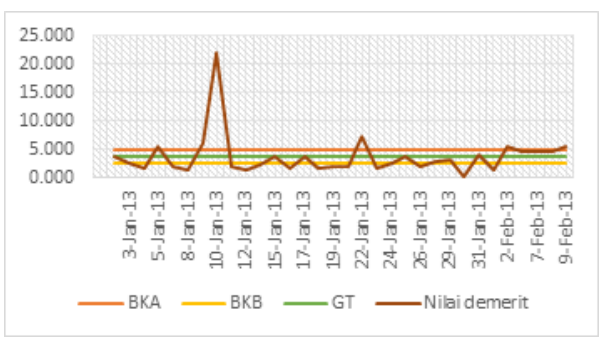

Gambar 2. Diagram Kendali Demerit Teh Botol Sosro

Berdasarkan gambar di atas terdapat lima titik yang berada di atas batas kendali atas yaitu tanggal 5 Januari, 9 Januari, 10 Januari, 22 Januari, dan 2 Februari. Sehingga dapat disimpulkan bahwa proses produksi tidak terkendali secara statistik. Faktor yang menyebabkan titik-titik tersebut berada di luar batas kendali adalah volume tidak standar. Kecacatan ini terjadi karena unit filling valve yang rusak sehingga dapat menyebabkan volume produk tidak sesuai dengan standar.

\section{Kesimpulan}

Berdasarkan analisis dan pembahasan terhadap proses produksi Teh Botol Sosro di PT KPB Ungaran maka dapat disimpulkan bahwa dengan metode Diagram Kendali Demerit, proses produksi pada rentang waktu 2 Januari 2013 sampai 9 Februari 2013 tidak terkendali disebabkan oleh 5 titik yang berada di atas batas kendali atas yang diakibatkan oleh volume tidak standar. Selain itu diperoleh jenis cacat yang mendominasi adalah jenis cacat mayor (suhu tidak standar dan volume tidak standar) dengan persentase $69 \%$ dari seluruh total produk cacat pada rentang produksi periode tersebut.

\section{Ucapan Terima Kasih}

Ucapan terima kasih kepada ibu Izzati Rahmi HG, bapak Dodi Devianto dan ibu Monika Rianti Helmi yang telah memberikan kritik dan saran untuk penulisan artikel ini. 
372 Fanny Primanda Piter dkk

\section{Daftar Pustaka}

[1] Grant E.L. dan R.S. Leavenworth. 1988. Pengendalian Mutu Statistik, Edisi ke-6. Penerbit Erlangga, Jakarta.

[2] Himawan. Pengendalian Kualitas Statistical Process Control Produk Genteng di UKM Super Soka Jepara. www.eprints.dinus.ac.id (diakses tanggal 30 September 2018)

[3] Montgomery. 2009. Introduction to Statistical Quality Control. John Wiley \& Sons. Inc, United States.

[4] Oakland. 2003. Statistical Process Control : Fifth Edition. Butterworth Heinemann, England.

[5] Santa, H. Kekuatan Merek Teh Botol Sosro. www.kompasiana.com. (diakses tanggal 28 November 2019)

[6] Taungke A.H. 2010. Pengendalian Kualitas Produk X Untuk Karakteristik Ph Dengan Menggunakan Grafik Pengendali Berdasarkan Densitas Kernel. Skripsi S1. Universitas Kristen Satya Wacana.

[7] Yemima. 2014. Penerapan Peta Kendali Demerit dan Diagram Pareto pada Pengontrolan Kualitas Produksi. Skripsi S1. Universitas Mulawarman.

[8] Tanpa nama. Tradisi Minum Teh Orang Indonesia. 2019. ¡https://www.unileverfoodsolutions.co.idi (diakses tanggal 2 Maret 2020)

[9] Tanpa nama. www.sinarsosro.id. (diakses 30 September 2018) 